\title{
Feasibility of Affibody-Based Bioorthogonal Chemistry-Mediated Radionuclide Pretargeting
}

\author{
Mohamed Altai ${ }^{1}$, Anna Perols ${ }^{2}$, Maria Tsourma ${ }^{1}$, Bogdan Mitran ${ }^{3}$, Hadis Honarvar ${ }^{1}$, Marc Robillard ${ }^{4}$, Raffaella Rossin ${ }^{4}$, \\ Wolter ten Hoeve ${ }^{5}$, Mark Lubberink ${ }^{6}$, Anna Orlova ${ }^{3}$, Amelie Eriksson Karlström² ${ }^{2}$, and Vladimir Tolmachev ${ }^{1}$ \\ ${ }^{1}$ Institute for Immunology, Genetics and Pathology, Uppsala University, Uppsala, Sweden; ${ }^{2}$ Division of Protein Technology, School of \\ Biotechnology, KTH Royal Institute of Technology, Stockholm, Sweden; ${ }^{3}$ Department of Medicinal Chemistry, Preclinical PET \\ Platform, Uppsala University, Uppsala, Sweden; ${ }^{4}$ Tagworks Pharmaceuticals, Eindhoven, The Netherlands; ${ }^{5}$ Syncom, Groningen, \\ The Netherlands; and ${ }^{6}$ Institute for Surgical Sciences, Radiology, Uppsala University, Uppsala, Sweden
}

\begin{abstract}
Affibody molecules constitute a new class of probes for radionuclide tumor targeting. The small size of Affibody molecules is favorable for rapid localization in tumors and clearance from circulation. However, high renal reabsorption of Affibody molecules prevents the use of residualizing radiometals, including several promising low-energy $\beta$ and $\alpha$-emitters, for radionuclide therapy. We tested a hypothesis that Affibody-based pretargeting mediated by a bioorthogonal interaction between trans-cyclooctene (TCO) and tetrazine would provide higher accumulation of radiometals in tumor xenografts than in the kidneys. Methods: TCO was conjugated to the anti-human epidermal growth factor receptor 2 (HER2) Affibody molecule $Z_{2395}$. DOTA-tetrazine was labeled with ${ }^{111}$ In and ${ }^{177} \mathrm{Lu}$. In vitro pretargeting was studied in HER2expressing SKOV-3 and BT474 cell lines. In vivo studies were performed on BALB/C nu/nu mice bearing SKOV-3 xenografts. Results: ${ }^{125} \mathrm{I}-\mathrm{Z}_{2395}$-TCO bound specifically to HER2-expressing cells in vitro with an affinity of $45 \pm 16 \mathrm{pM}$. ${ }^{111}$ In-tetrazine bound specifically and selectively to $Z_{2395}-$ TCO pretreated cells. In vivo studies demonstrated HER2specific ${ }^{125} \mathrm{I}-Z_{2395}-\mathrm{TCO}$ accumulation in xenografts. TCO-mediated 111 In-tetrazine localization was shown in tumors, when the radiolabeled tracer was injected $4 \mathrm{~h}$ after an injection of $Z_{2395}-\mathrm{TCO}$. At $1 \mathrm{~h}$ after injection, the tumor uptake of ${ }^{111} \mathrm{In}$-tetrazine and ${ }^{177}$ Lu-tetrazine was approximately 2-fold higher than the renal uptake. Pretargeting provided more than a 56-fold reduction of renal uptake of ${ }^{111} \mathrm{I} \mathrm{n}$ in comparison with direct targeting. Conclusion: The feasibility of Affibody-based bioorthogonal chemistry-mediated pretargeting was demonstrated. The use of pretargeting provides a substantial reduction of radiometal accumulation in kidneys, creating preconditions for palliative radionuclide therapy.
\end{abstract}

Key Words: affibody; tetrazine; trans-cyclooctene; radionuclide pretargeting; engineered scaffold protein; radionuclide therapy

J Nucl Med 2016; 57:431-436

DOI: 10.2967/jnumed.115.162248

$\mathbf{R}$ adionuclide targeting of tumor-specific overexpressed cell surface proteins has a potential to improve cancer therapy. Radionuclide imaging might help to identify patients with tumors expressing a particular target and therefore would be likely to respond to a particular therapy based on antibodies or tyrosine kinase inhib-

For correspondence contact: Vladimir Tolmachev, Institute for Immunology, Genetics and Pathology, Uppsala University, Se-75185, Uppsala, Sweden.

E-mail: Vladimir.tolmachev@igp.uu.se

Published online Dec. 10, 2015.

COPYRIGHT (c) 2016 by the Society of Nuclear Medicine and Molecular Imaging, Inc. itors (1). Delivery of cytotoxic radionuclides (e.g., $\beta$ - or $\alpha$-emitters) might have strong palliative or even curative effects (2).

Two classes of substances have commonly been exploited for radionuclide targeting: monoclonal antibodies (and their derivatives) and peptide ligands to receptors overexpressed in tumors. Engineered scaffold proteins (ESPs) constitute a new type of targeting agents for radionuclide tumor targeting (3). ESPs contain a robust framework providing conformational stability and variable surface amino acids. Randomization of variable amino acids enables selection of high-affinity binders to different proteins using molecular display technology. Several ESPs, such as Affibody (Affibody AB) molecules (4), designed ankyrin repeat proteins (5), fibronectin domains (6), anticalins (7), cysteine-knot peptides (8), and albumin-binding domain-derived affinity proteins (ADAPTs) (9), have been successfully used for radionuclide imaging of therapeutic targets in preclinical studies. Anti-HER2 Affibody molecules have demonstrated sensitive and specific imaging of HER2-expressing metastases of disseminated breast cancer in a clinical trial (10). The small size (4-20 kDa) of ESPs permits rapid extravasation and diffusion in the extracellular space, improving targeting. Rapid clearance of unbound tracer provides low background during imaging and low exposure of radiosensitive bone marrow during therapy. However, many radiometal-labeled ESPs have high renal uptake $(5,6,9,11)$. For example, Affibody molecules and ADAPTs or products of their in vivo degradation undergo efficient renal reabsorption after glomerular filtration, followed by proteolysis in the proximal tubuli $(9,11)$. In the case of residualizing radiometal labels, this results in a renal uptake that substantially exceeds the tumor uptake, making radionuclide therapy using unmodified ESPs problematic.

Earlier, we showed that it is possible to appreciably reduce the renal uptake of radionuclides using Affibody molecules with nonresidualizing labels. Internalization of Affibody molecules by cancer cells is slow (12-14), and the residualizing properties of a radionuclide are not critical for good tumor retention. Internalization of Affibody molecules in proximal tubuli and the following proteolytic degradation is rapid; radiocatabolites of nonresidualizing labels (radioiodine and ${ }^{186 / 188} \mathrm{Re}$ in combination with some chelators) are cleared rapidly from the kidneys (15-17). This approach provided a residence time in tumors that was longer than in the kidneys. There are, however, certain limitations of this approach. High-energy $\beta$-particles emitted by rhenium isotopes are better suited for treatment of bulky tumors, not small metastases. Low-energy $\beta$-particles of ${ }^{131}$ I are suitable for treatment of small metastases, but the highabundance high-energy $\gamma$-quanta emitted by this nuclide contribute 
appreciably to the whole-body irradiation (18). Finding an approach for the reduction of renal uptake/retention of residualizing radiometal labels would enable the use of low-energy $\beta$-emitters, such as ${ }^{177} \mathrm{Lu}$ and ${ }^{161} \mathrm{~Tb}$, or $\alpha$-emitting nuclides, such as ${ }^{213} \mathrm{Bi}$, ${ }^{225} \mathrm{Ac}$, and ${ }^{227} \mathrm{Th}$. This approach would provide an efficient way to treat small metastases.

A possible way to solve the issue of high renal retention of radiometals is the application of pretargeting (19). Pretargeting is a 2-step process. At the first step, a primary agent containing a recognition tag is injected. When the primary agent is localized in the tumor and cleared from circulation, a radiolabeled secondary agent having high affinity to the recognition tag is injected. The secondary agent is selected to have a better biodistribution profile in comparison with the primary agent. Several approaches to pretargeting have been investigated, including variants based on avidin-biotin interaction (20), hybridization of complementary nucleic acid analogs (21), bispecific antibody-hapten interaction (22), and bioorthogonal chemistry (23). However, many hours might be required to clear a primary agent completely from the blood if it is antibody-based. Incomplete clearance would cause an interception of the radiolabeled secondary agent in the blood and prolonged circulation time of the radiolabel. Antibodies bound to cancer cells might be internalized, and a long waiting time before injection of the secondary agent is associated with the disappearance of antibody-recognition tag conjugates from the cell surface.

The use of pretargeting is favorable for ESPs, because these agents are often slowly internalized by malignant cells and clear rapidly, within a few hours, from the blood $(9,12-14)$. This ensures that a large number of recognition tags would remain on the surface of pretargeted malignant cells at the time of injection of the radiolabeled secondary agent.

The use of bioorthogonal chemistry based on the inverse-electrondemand Diels-Alder reaction between trans-cyclooctene (TCO) and tetrazine $(23,24)$ seems to be an attractive approach for ESP-based pretargeting. Radiometal-labeled DOTA-conjugated tetrazine has low uptake in kidneys (23). Reengineering of the primary agent is not required for modification with TCO. Incorporation of a unique cysteine into the cysteine-free scaffold of Affibody molecules or ADAPTs can provide site-specific conjugation of TCO tags in a controllable manner.

The goal of this study was to test the hypothesis that the use of ESP-based bioorthogonal chemistry-mediated pretargeting enables specific tumor targeting and provides higher uptake of radiometals in tumors than in the kidneys. An anti-HER2 Affibody molecule $\mathrm{Z}_{2395}$ containing a $\mathrm{C}$-terminal cysteine was used as a model ESP. A maleimido derivative of TCO was sitespecifically conjugated to $Z_{2395}$ (Fig. 1). The specificity of $\mathrm{Z}_{2395}$-TCO targeting of HER2-expressing cells was evaluated in vitro and in vivo.

\section{MATERIALS AND METHODS}

A detailed description of materials, equipment, and some methods used in this study is given in the supplemental data (available at http:// jnm.snmjournals.org).

\section{Conjugation and Labeling}

Detailed descriptions of the conjugation of maleimido derivative of TCO to the $Z_{2395}$ Affibody molecule, radioiodination of $Z_{2395}$-TCO conjugate, and labeling of DOTA-decaethylene glycol $\left(\mathrm{PEG}_{10}\right)$-tetrazine with ${ }^{111} \mathrm{In}$ and ${ }^{177} \mathrm{Lu}$ are presented in the supplemental data.

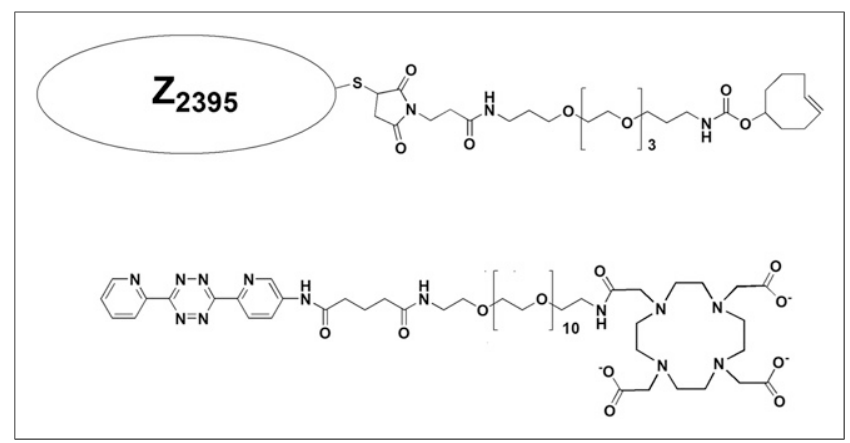

FIGURE 1. Structure of primary targeting conjugate TCO-PEG $4-Z_{2395}$ (top) and secondary targeting agent DOTA-PEG ${ }_{10}$-tetrazine (bottom).

\section{In Vitro Evaluation}

HER2-expressing ovarian carcinoma SKOV-3 $\left(1.6 \times 10^{6}\right.$ receptors/ cell) and breast carcinoma BT474 $\left(2 \times 10^{6}\right.$ receptors/cell $)$ cell lines were used in in vitro studies. Binding specificity, affinity of $Z_{2395}-\mathrm{TCO}$ to HER2, cellular retention of primary targeting agent, cellular processing, and internalization of ${ }^{111} \mathrm{In}$-tetrazine-TCO-Z $\mathrm{Z}_{2395}$ adduct were studied as described in the supplemental data. Cellular processing and internalization were evaluated using a previously validated method for Affibody molecules (12).

\section{In Vivo Studies}

The animal experiments were planned and performed in accordance with national legislation on laboratory animals' protection. The animal study was approved by the Ethics Committee for Animal Research in Uppsala, Sweden.

SKOV-3 cells $\left(8 \times 10^{6}\right.$ cells per mouse $)$ were implanted in the right hind leg of female BALB/C nu/nu mice. The average animal weight was $18.4 \pm 1.6 \mathrm{~g}$, and the average tumor weight was $0.24 \pm 0.11 \mathrm{~g}$ at the time of the experiment. Mice were divided into 13 groups $(n=4-6)$. At the end of each experiment, the mice were anesthetized and euthanized by cervical dislocation. Blood was withdrawn by heart puncture. The organ and tissue samples were collected and weighed, and their radioactivity was measured along with standards to determine the percentage injected dose per gram $(\% \mathrm{ID} / \mathrm{g})$. In the case of dual-nuclide studies, whole spectra of each sample were recorded. For ${ }^{125} \mathrm{I}$ measurements, counts in the energy window of $4-70 \mathrm{keV}$ were integrated, and for ${ }^{111} \mathrm{In}$, in the window of $110-600 \mathrm{keV}$. The data were corrected for background, dead time, and spillover.

In Vivo Specificity of ${ }^{125} I-Z_{2395}-T C O$ and Tetrazine. Two groups of mice were injected intravenously with $5 \mu \mathrm{g}(0.67 \mathrm{nmol})$ of ${ }^{125} \mathrm{I}-$ $\mathrm{Z}_{2395}$-TCO $(5 \mu \mathrm{g} / 100 \mu \mathrm{L}$ of phosphate-buffered saline [PBS] per mouse, $\sim 10 \mathrm{kBq}$ ). To check the HER2 specificity of xenograft targeting, 1 group $(n=4)$ was subcutaneously injected with $500 \mu \mathrm{g}(66 \mathrm{nmol})$ of nonlabeled recombinant $Z_{\mathrm{HER} 2: 342}$ Affibody molecule $45 \mathrm{~min}$ before injection of ${ }^{125} \mathrm{I}_{-} \mathrm{Z}_{2395}$-TCO. Mice were sacrificed at $5 \mathrm{~h}$ after injection. The second group $(n=6)$ was injected with $1 \mu \mathrm{g}(\sim 0.7 \mathrm{nmol})$ of ${ }^{111}$ In-tetrazine $(1 \mu \mathrm{g} / 100 \mu \mathrm{L}$ of PBS per mouse, $\sim 30 \mathrm{kBq}) 4 \mathrm{~h}$ after injection of ${ }^{125} \mathrm{I}_{-Z_{2395}}-\mathrm{TCO}$, to test the feasibility of in vivo pretargeting. An extra group $(n=4)$ was injected only with $1 \mu \mathrm{g}$ of ${ }^{111}$ In-tetrazine $(\sim 0.7 \mathrm{nmol})$. Mice were sacrificed $1 \mathrm{~h}$ after injection of ${ }^{111} \mathrm{In}$-tetrazine, and tissue samples were treated as mentioned above.

Influence of Injected Dose of Both Primary $\left(Z_{2395}-T C O\right)$ and Secondary (Tetrazine) Agents on Pretargeting. Two groups of mice $(n=5)$ were injected intravenously with $30 \mu \mathrm{g}(4.1 \mathrm{nmol})$ of ${ }^{125} \mathrm{I}_{-} \mathrm{Z}_{2395}-\mathrm{TCO}$ ( $30 \mu \mathrm{g} / 100 \mu \mathrm{L}$ of PBS per mouse, $\sim 30 \mathrm{kBq}$ ). Four hours after injection of ${ }^{125} \mathrm{I}_{-} \mathrm{Z}_{2395}$-TCO, mice were injected either with $5.2 \mu \mathrm{g}(4.1 \mathrm{nmol})$ of ${ }^{111}$ In-tetrazine (1:1 tetrazine-to- $Z_{2395}$-TCO ratio, $100 \mu \mathrm{L}$ of PBS 


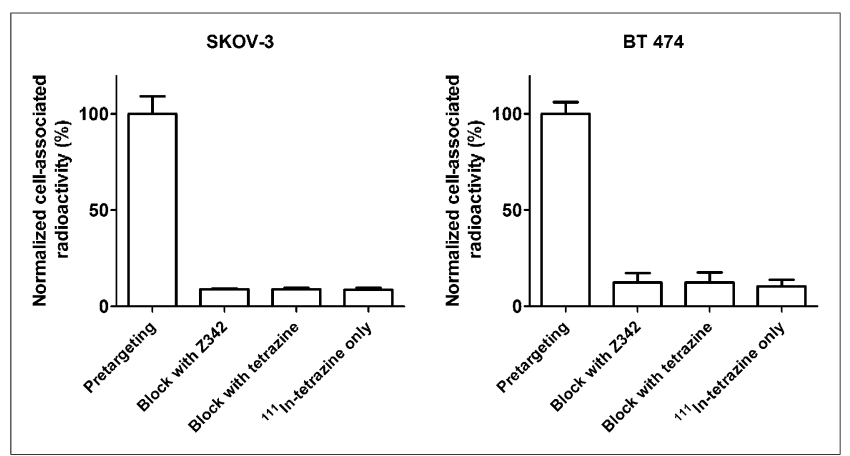

FIGURE 2. Binding of ${ }^{111} \mathrm{In}$-tetrazine to SKOV-3 (left) and BT474 (right) cells when cells were preincubated with Z2395-TCO for $1 \mathrm{~h}$ before addition of ${ }^{111}$ In-tetrazine (first bar in graph), when cells were incubated with excess of unlabeled anti-HER2 Affibody molecule ZHER2:342 for 10 min followed by addition of Z2395-TCO and 111 In-tetrazine (second bar), when cells were preincubated with Z2395-TCO followed by addition of excess unlabeled tetrazine and then ${ }^{111} \mathrm{In}$-tetrazine (third bar), and when ${ }^{111} \mathrm{In}$-tetrazine was added directly to cells (fourth bar). Data represent average \pm SD $(n=3)$.

per mouse, $\sim 30 \mathrm{kBq})$ or with $26 \mu \mathrm{g}(20.5 \mathrm{nmol})$ of ${ }^{111}$ In-tetrazine (5:1 tetrazine-to- $Z_{2395}$-TCO ratio, $100 \mu \mathrm{L}$ of PBS per mouse, $\sim 30 \mathrm{kBq}$ ). One hour after injection of ${ }^{111}$ In-tetrazine, the animals were sacrificed and the biodistribution was measured.

In the case of ${ }^{177} \mathrm{Lu}$-tetrazine, 3 groups of mice $(n=5)$ were injected with $Z_{2395}-\mathrm{TCO}(30 \mu \mathrm{g} / 4.1 \mathrm{nmol})$. Four hours later, mice were injected with ${ }^{177} \mathrm{Lu}$-tetrazine to provide tetrazine: $Z_{2395}$-TCO ratios of 2:1 (10.4 $\mu \mathrm{g} / 8.2 \mathrm{nmol}), 1: 1(5.2 \mu \mathrm{g} / 4.1 \mathrm{nmol})$, and 1:5 (1.04 $\mu \mathrm{g} / 0.82$ nmol). The biodistribution was measured at $1 \mathrm{~h}$ after injection of ${ }^{177}$ Lu-tetrazine.

Influence of Time of Injection of Secondary Agent. Three groups of tumor-bearing mice $(n=4)$ were injected with $30 \mu \mathrm{g}(4.1 \mathrm{nmol})$ of $\mathrm{Z}_{2395}$-TCO (30 $\mu \mathrm{g} / 100 \mu \mathrm{L}$ of PBS per mouse, $\left.\sim 30 \mathrm{kBq}\right)$. Four, 8 , and $14 \mathrm{~h}$ after Affibody injection, the mice received $5.2 \mu \mathrm{g}(4.1 \mathrm{nmol})$ of ${ }^{177} \mathrm{Lu}$-tetrazine (1:1 tetrazine-to- $\mathrm{Z}_{2395}$-TCO ratio, $100 \mu \mathrm{L}$ of PBS per mouse, $\sim 130 \mathrm{kBq}$ ). The biodistribution was measured at $1 \mathrm{~h}$ after injection of ${ }^{177} \mathrm{Lu}$-tetrazine.

Dosimetry Evaluation. Five groups of mice $(n=4)$ were injected intravenously with $30 \mu \mathrm{g}(4.1 \mathrm{nmol})$ of $\mathrm{Z}_{2395}$-TCO. Four hours later, mice were injected with $5.2 \mu \mathrm{g}(4.1 \mathrm{nmol})$ of ${ }^{177} \mathrm{Lu}$-tetrazine (1:1 tetrazineto- $\mathrm{Z}_{2395}$-TCO ratio, $100 \mu \mathrm{L}$ of PBS per mouse, $\left.\sim 130 \mathrm{kBq}\right)$. The biodistribution was measured at 1, 4, 24, 72, and $168 \mathrm{~h}$ after ${ }^{177} \mathrm{Lu}$-tetrazine injection. Radiation dosimetry was estimated as described the supplemental data.

\section{Imaging Using SPECT/CT}

To confirm the capacity of an Affibody-based Diels-Alder pretargeting to target HER2-expressing tumors in vivo, an imaging experi-
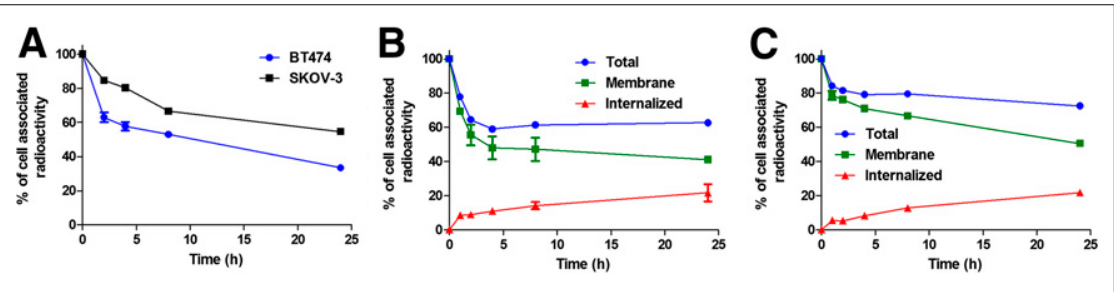

FIGURE 3. Cellular retention of ${ }^{125} \mathrm{I}-\mathrm{Z}_{2395}$-TCO (A) and processing of ${ }^{111} \mathrm{In}$-tetrazine- $\mathrm{Z}_{2395}-\mathrm{TCO}$ by BT474 (B) and SKOV-3 (C) cells. Data represent average \pm SD $(n=3)$. ment was performed as described in the supplemental data. Images were acquired at $1 \mathrm{~h}$ after ${ }^{111} \mathrm{In}$-tetrazine injection.

\section{RESULTS}

\section{Conjugation and Labeling}

The efficacy of maleimido- $\mathrm{PEG}_{4}-\mathrm{TCO}$ conjugation was $23.5 \% \pm$ $0.5 \%$. The high-performance liquid chromatography purification of the conjugate provided a purity of greater than $90 \%$ (Supplemental Fig. 1A). The mass spectrum of the purified $\mathrm{Z}_{2395}$-TCO (calculated weight, 7,525 Da; found, 7,525.6) is shown in Supplemental Figure 1B.

$\mathrm{Z}_{2395}$-TCO was indirectly radiolabeled with ${ }^{125} \mathrm{I}$ in $18.9 \% \pm$ $0.3 \%$ radiochemical yield with a specific activity of $0.07 \mathrm{MBq} / \mu \mathrm{g}$ $(0.5 \mathrm{MBq} / \mathrm{nmol})$. The radiochemical purity of ${ }^{125} \mathrm{I}_{-} \mathrm{Z}_{2395}-\mathrm{TCO}$ was $99.4 \% \pm 0.4 \%$. DOTA-tetrazine was efficiently labeled with ${ }^{111} \mathrm{In}$ and ${ }^{177} \mathrm{Lu}$. For ${ }^{111} \mathrm{In}$, the labeling yield was $99.5 \% \pm 0.5 \%$ $(n=9)$, and the specific activity was $1.44 \mathrm{MBq} / \mathrm{nmol}$. For ${ }^{177} \mathrm{Lu}$, the yield was $99.4 \% \pm 0.5 \%(n=5)$, and the specific activity of 23.6 MBq/nmol was achieved. The high yields excluded the need for further purification, and the labeled compound was diluted with PBS for further experiments. The gel electrophoresis confirmed the identity and purity of labeled tetrazine (data not shown).

\section{In Vitro Binding Specificity and Affinity}

In vitro binding of ${ }^{111}$ In-tetrazine to $\mathrm{Z}_{2395}$-TCO pretreated HER2expressing cells exceeded nonspecific uptake by untreated cells 10fold ( $P<0.05 ;$ Fig. 2 ). There was a highly significant reduction of ${ }^{111}$ In-tetrazine binding to both cell lines when $\mathrm{Z}_{2395}$-TCO binding was prevented by presaturation of receptors using nonlabeled antiHER2 Affibody or under competition with a large excess of nonlabeled tetrazine (Fig. 2). These data demonstrate that ${ }^{111}$ In-tetrazine binding depends on the interaction of $\mathrm{Z}_{2395}$-TCO with HER2 and on the interaction of tetrazine with TCO and confirm in vitro pretargeting.

According to LigandTracer (Ridgeview Instruments $\mathrm{AB}$ ) measurements, the dissociation constant at equilibrium $\left(\mathrm{K}_{\mathrm{D}}\right)$ for binding of ${ }^{125} \mathrm{I}_{-} \mathrm{Z}_{2395}$-TCO HER2-expressing cells was $45 \pm 16 \mathrm{pM}$. The $K_{D}$ for ${ }^{111}$ In-tetrazine- $Z_{2395}$-TCO was $9 \pm 7$ pM.

The cellular retention of ${ }^{125} \mathrm{I}_{-} \mathrm{Z}_{2395}$-TCO by HER2-expressing cells is presented in Figure 3A. The retention profile was similar for both cell lines: an initial decrease of cell-associated activity followed by slower decline. The retention was better for SKOV-3 than for BT474: $54.6 \% \pm 0.5 \%$ versus $33.4 \% \pm 0.5 \%$ at $24 \mathrm{~h}$, respectively.

The data concerning the cellular processing and internalization of ${ }^{111}$ In-tetrazine-TCO-Z 2395 are presented in Figures 3B and 3C. The radioactivity was efficiently retained by HER2-expressing cells. The overall retention of the conjugate by SKOV-3 cells was higher than that for BT474. Internalization was slow, with most of the retained radioactivity being membranebound. Apparently, cellular retention of the total radioactivity was quite good, with $63 \pm 1.7$ and $72 \% \pm 2 \%$ of cell-associated radioactivity retained after $24 \mathrm{~h}$ of incubation at $37^{\circ} \mathrm{C}$ in $\mathrm{BT} 474$ and SKOV-3, respectively. On the other hand, the internalization of ${ }^{111}$ In-tetrazine-TCO-Z 2395 was relatively slow, with only $30 \% \pm 2 \%$ (BT474) and $22 \% \pm 1 \%$ (SKOV3) of total cell-associated radioactivity internalized at $24 \mathrm{~h}$. 


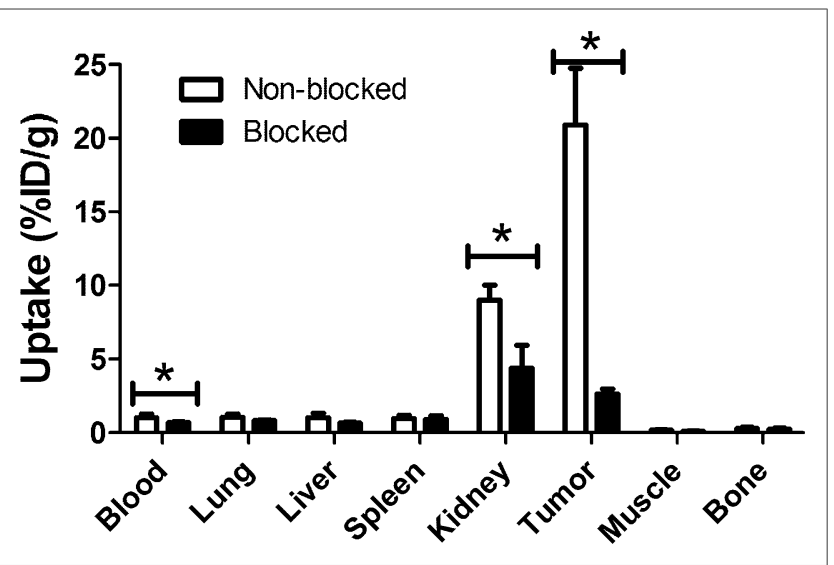

FIGURE 4. In vivo targeting specificity of ${ }^{125} \mathrm{I}-\mathrm{Z}_{2395}-\mathrm{TCO}$ in mice bearing SKOV-3 xenografts at $5 \mathrm{~h}$ after injection. Blocked group was subcutaneously preinjected with excess amount of nonlabeled Affibody molecule. Data represent average $\pm \mathrm{SD}(n=5)$. ${ }^{\star}$ Significant difference $(P<0.05)$.

\section{In Vivo Studies}

The results of the in vivo specificity test showed that tumor accumulation of primary targeting agent $\mathrm{Z}_{2395}$-TCO is HER2-mediated. Presaturation of HER2 decreased the tumor-associated radioactivity from $21 \pm 4$ to $2.6 \pm 0.3 \% \mathrm{ID} / \mathrm{g}$ (Fig. 4). Both blood and kidneys also showed a significantly lower concentration of radioactivity in the blocking group.

A comparison of ${ }^{111}$ In-tetrazine biodistribution (1 h after injection) with and without preinjection of $\mathrm{Z}_{2395}$-TCO is presented in Figure 5. In the case of preinjection, the tumor uptake $(3.2 \pm 0.7 \% \mathrm{ID} / \mathrm{g})$ was approximately 20 -fold higher than without preinjection $(0.16 \pm 0.02$ $\% \mathrm{ID} / \mathrm{g})(P<0.0005)$. The uptake in normal organs and tissues was also significantly (2- to 3-fold) higher after preinjection $(P<0.05)$.

Increasing the injected dose of ${ }^{125} \mathrm{I}_{-} \mathrm{Z}_{2395}$-TCO from $5 \mu \mathrm{g}(0.67$ $\mathrm{nmol})$ to $30 \mu \mathrm{g}(4.1 \mathrm{nmol})$ showed a significant but small difference in tissue-associated radioactivity including the tumor $(21 \pm 4$ vs. $17 \pm$ $2 \% \mathrm{ID} / \mathrm{g}$ ) (Supplemental Fig. 2A). However, the higher dose of ${ }^{125} \mathrm{I}_{-} \mathrm{Z}_{2395}$-TCO $(30 \mu \mathrm{g} / 4.1 \mathrm{nmol})$ increased the tumor localization of ${ }^{111}$ In-tetrazine significantly from $3.2 \pm 0.7$ to $9.7 \pm 1.6 \% \mathrm{ID} / \mathrm{g}$ (Table 1; Supplemental Fig. 2B). At this higher Affibody dose, there was no increase of ${ }^{111}$ In-tetrazine accumulation in other organs and the tumor-to-kidney ratio was $2.1 \pm 0.5$. The uptake of ${ }^{177} \mathrm{Lu}$-tetrazine was significantly lower than ${ }^{111}$ In-tetrazine in almost all organs including the tumor $(5.4 \pm 0.8$ vs. $9.7 \pm 1.6 \% \mathrm{ID} / \mathrm{g})$ and kidneys $(2.5 \pm 0.3$ vs. $5 \pm 2 \% \mathrm{ID} / \mathrm{g})$ (Table 1$)$. Because of the more rapid blood clearance of ${ }^{177} \mathrm{Lu}$-tetrazine, the tumor-to-blood ratio for ${ }^{177} \mathrm{Lu}$-tetrazine $(19.5 \pm 2.2)$ was higher than for ${ }^{111}$ In-tetrazine $(5.7 \pm 0.8)$. However the tumor-to-kidney ratio was the same.

The tumor-associated radioactivity was significantly reduced $(P<$ 0.05 ) when the injected ${ }^{111}$ In-tetrazine-to- $\mathrm{Z}_{2395}$ TCO ratio was increased by 5 -fold $(9.7 \pm 1.6$ vs. $2.9 \pm 0.4 \% \mathrm{ID} / \mathrm{g}$ ) (Table 1; Supplemental Fig. 3). As a result, the tumor-to-kidney ratio decreased to $0.8 \pm 0.1$. There was no significant difference between the tumor uptake of ${ }^{177} \mathrm{Lu}$-tetrazine when the tetrazine-to- $\mathrm{Z}_{2395}$-TCO ratio was $2: 1(3.8 \pm 1.0 \% \mathrm{ID} / \mathrm{g})$ and $1: 1(4.8 \pm 1.3 \% \mathrm{ID} / \mathrm{g})$. The use of $\mathrm{a}$ tetrazine-to- $\mathrm{Z}_{2395} \mathrm{TCO}$ ratio of 1:5 resulted in a significant reduction of the tumor uptake $(0.9 \pm 0.1 \% \mathrm{ID} / \mathrm{g})$ (Fig. 6A)

Increasing the time between injections of the primary and secondary agents from 4 to $8 \mathrm{~h}$ did not result in any significant difference in ${ }^{177}$ Lu-tetrazine tumor uptake $(4.8 \pm 1.3$ vs. $4.6 \pm 0.8$
$\%$ ID/g) (Fig. 6B). The tumor localization of ${ }^{177} \mathrm{Lu}$-tetrazine decreased significantly when the secondary agent was injected $14 \mathrm{~h}$ after $\mathrm{Z}_{2395}$-TCO injection.

Measurement of ${ }^{177} \mathrm{Lu}$-tetrazine biodistribution up to $1 \mathrm{wk}$ after radioactivity injection demonstrated that tumors and kidneys were the only organs with noticeable retention of radioactivity (Supplemental Table 1). Calculated areas under curves are presented in Supplemental Table 2. The calculated areas under curves were bigger for the tumors than for any other tissue, including the kidneys.

The estimated absorbed doses for pretargeted ${ }^{177} \mathrm{Lu}$-tetrazine in humans are presented in Supplemental Table 3. The primary critical organ for ${ }^{177}$ Lu-tetrazine pretargeting was the kidney $(0.021 \mathrm{mGy} / \mathrm{MBq})$. The effective dose for pretargeted tetrazine is $0.005 \mathrm{mSv} / \mathrm{MBq}$.

Imaging confirmed the results of the biodistribution experiments. The tumor xenografts were the only sites with prominent accumulation of radioactivity $1 \mathrm{~h}$ after injection of Affibody-pretargeted ${ }^{111}$ In-tetrazine (Fig. 7A).

\section{DISCUSSION}

Radionuclide pretargeting is usually applied in combination with monoclonal antibodies or their derivatives to reduce the residence time of a radionuclide in blood and spare the bone marrow. Here, pretargeting is used for correction of the undesirable biodistribution profile of a small targeting protein having rapid clearance and high kidney uptake.

This study demonstrated that ${ }^{125} \mathrm{I}_{-} \mathrm{Z}_{2395}$-TCO retained picomolar affinity to HER2-expressing cell lines. In vitro binding of ${ }^{111}$ In-tetrazine to $\mathrm{Z}_{2395}$-TCO-treated cells was clearly dependent on tetrazine-TCO interaction and based on specific binding of $\mathrm{Z}_{2395^{-}}$ TCO to HER2-expressing cells (Fig. 2).

An in vivo specificity test (Fig. 4) demonstrated a high (21 \pm 4 $\% \mathrm{ID} / \mathrm{g}$ at $5 \mathrm{~h}$ after injection) specific uptake of ${ }^{125} \mathrm{I}-\mathrm{Z}_{2395}$-TCO in HER2-expressing SKOV-3 xenografts. Apparently, the use of a $\mathrm{PEG}_{4}$ linker was sufficient to counterbalance the lipophilicity of TCO, because hepatic uptake of ${ }^{125} \mathrm{I}-\mathrm{Z}_{2395}$-TCO was low, at only $1.0 \pm 0.3 \% \mathrm{ID} / \mathrm{g}$. In agreement with earlier data (25), an increased injected dose of ${ }^{125} \mathrm{I}_{-} \mathrm{Z}_{2395}$-TCO to $30 \mu \mathrm{g}(4.1 \mathrm{nmol})$ reduced the tumor uptake only marginally, from $21 \pm 4$ to $17 \pm 2 \% \mathrm{ID} / \mathrm{g}$ (Supplemental Fig. 2A).

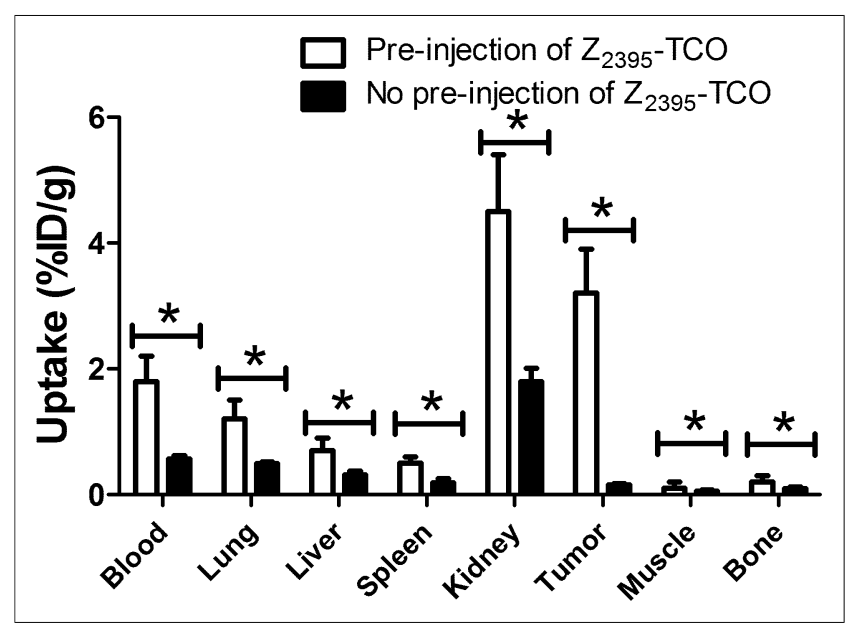

FIGURE 5. Biodistribution of ${ }^{111} \mathrm{In}$-tetrazine in mice bearing SKOV-3 xenografts (no preinjection) and when mice were intravenously preinjected with $5 \mu \mathrm{g}(0.67 \mathrm{nmol})$ of $Z_{2395}-\mathrm{TCO}$ (preinjection). Data are presented as average $\pm \operatorname{SD}(n=5)$. ${ }^{*}$ Significant difference $(P<0.05)$. 
TABLE 1

Biodistribution of ${ }^{111} \mathrm{In}$-Tetrazine in BALB/C nu/nu Mice Bearing SKOV-3 Xenografts at 1 Hour After Injection

\begin{tabular}{lccc}
\hline & \multicolumn{2}{c}{${ }^{111} \mathrm{In}$} & ${ }^{177 \mathrm{Lu}}$ \\
\cline { 2 - 4 } Organ & $\begin{array}{c}\text { Injected dose of tetrazine } \\
(\mu \mathrm{g} / \mathrm{nmol}), 5.2 / 4.1(1: 1)\end{array}$ & $\begin{array}{c}\text { Injected dose of tetrazine } \\
(\mu \mathrm{g} / \mathrm{nmol}), 26 / 20.5(5: 1)\end{array}$ & $\begin{array}{c}\text { Injected dose of tetrazine } \\
(\mu \mathrm{g} / \mathrm{nmol}), 5.2 / 4.1(1: 1)\end{array}$ \\
\hline Blood & $1.7 \pm 0.4$ & $1.3 \pm 0.1$ & $0.27 \pm 0.02^{\star}$ \\
Lung & $1.1 \pm 0.1$ & $1.1 \pm 0.23$ & $0.47 \pm 0.09^{\star}$ \\
Liver & $0.6 \pm 0.1$ & $0.53 \pm 0.07$ & $0.25 \pm 0.02^{\star}$ \\
Spleen & $0.4 \pm 0.1$ & $0.4 \pm 0.1$ & $0.13 \pm 0.02^{\star}$ \\
Kidney & $5 \pm 2$ & $3.8 \pm 0.7$ & $2.5 \pm 0.3^{\star}$ \\
Tumor & $9.7 \pm 1.6$ & $2.9 \pm 0.4$ & $5.4 \pm 0.8^{\star}$ \\
Muscle & $0.3 \pm 0.2$ & $0.13 \pm 0.03$ & $0.14 \pm 0.17$ \\
Bones & $0.3 \pm 0.1$ & $0.18 \pm 0.04$ & $0.14 \pm 0.08$
\end{tabular}

*Significant difference between ${ }^{111} \mathrm{In} /{ }^{177}$ Lu-tetrazine.

$\mathrm{Z}_{2395} \mathrm{TCO}(30 / 4.1 \mathrm{\mu g} / \mathrm{nmol})$ was preinjected $4 \mathrm{~h}$ before ${ }^{111} \mathrm{In}$-tetrazine. Data are presented as an average $\% \mathrm{ID} / \mathrm{g} \pm \mathrm{SD}(n=5)$, with molar ratios between ${ }^{111} \mathrm{In} /{ }^{177} \mathrm{Lu}$-tetrazine and $\mathrm{Z}_{2395}-\mathrm{TCO}$ in parentheses.

This increased dose of $30 \mu \mathrm{g}$ allowed for an increasing amount of TCO to be delivered to the tumors, from $0.14 \pm 0.03$ to $0.70 \pm 0.08$ $\mathrm{nmol} / \mathrm{g}$, resulting in a more than 3 -fold increase of ${ }^{111}$ In-tetrazine localization in xenografts (Table 1; Supplemental Fig. 2B). Importantly, uptake of ${ }^{111}$ In-tetrazine did not increase in any other organ or tissue.

Comparison of ${ }^{111} \mathrm{In}$-tetrazine biodistribution with and without preinjection of $\mathrm{Z}_{2395}$-TCO (Fig. 5) demonstrates that the tumor uptake of ${ }^{111}$ In-tetrazine is TCO-mediated. In addition, an increase of tetrazineto-Affibody ratio from $1: 1(5.2 \mu \mathrm{g} / 4.1 \mathrm{nmol}: 30 \mu \mathrm{g} / 4.1 \mathrm{nmol})$ to $5: 1$ $(26 \mu \mathrm{g} / 20.5 \mathrm{nmol}: 30 \mu \mathrm{g} / 4.1 \mathrm{nmol})$ decreased tumor uptake significantly $(P<0.05)$ (Table 1; Supplemental Fig. 3), which suggests a saturable character of tetrazine accumulation in $\mathrm{Z}_{2395}$-TCO-treated xenografts. Taken together, this gives strong evidence that localization of radionuclide is mediated by interaction of tetrazine with TCO.

The most remarkable aspect was the low renal uptake of ${ }^{111} \mathrm{In}$ tetrazine, $5 \pm 2 \% \mathrm{ID} / \mathrm{g}$ (injected $\mathrm{Z}_{2395}$-TCO dose of $30 \mu \mathrm{g} / 4.1 \mathrm{nmol}$, tetrazine-to-Affibody ratio 1:1). Earlier, we evaluated biodistribution of $Z_{2395}$, which was labeled with ${ }^{111}$ In using DOTA conjugated to the C-terminal cysteine (26). The same mouse strain, BALB/C

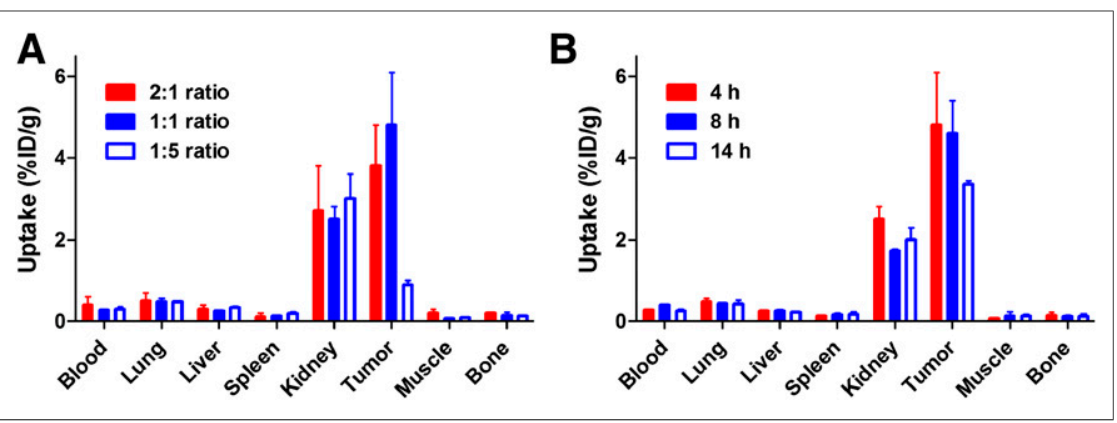

FIGURE 6. Factors influencing pretargeting of 177 Lu-tetrazine in mice bearing SKOV-3 xenografts. All mice were preinjected with $30 \mu \mathrm{g} / 4.1 \mathrm{nmol} \mathrm{Z}_{2395}$-TCO. (A) Biodistribution of ${ }^{177} \mathrm{Lu}$-tetrazine at $1 \mathrm{~h}$ after injection. Mice were preinjected with $Z_{2395}-\mathrm{TCO} 4 \mathrm{~h}$ before injection of ${ }^{177} \mathrm{Lu}$-tetrazine. Tetrazineto- $Z_{2395}$-TCO molar ratios were 2:1 $(10.4 \mu \mathrm{g} / 8.2 \mathrm{nmol}: 30 \mu \mathrm{g} / 4.1 \mathrm{nmol}), 1: 1(5.2 \mu \mathrm{g} / 4.1 \mathrm{nmol}: 30 \mu \mathrm{g} /$ $4.1 \mathrm{nmol})$, and 1:5 (1.04 $\mu \mathrm{g} / 0.82 \mathrm{nmol}: 30 \mu \mathrm{g} / 4.1 \mathrm{nmol})$. (B) Biodistribution of ${ }^{177}$ Lu-tetrazine $(4.1 \mathrm{nmol})$ at $1 \mathrm{~h}$ after injection when mice were preinjected with $\mathrm{Z}_{2395}$-TCO 4,8 , and $14 \mathrm{~h}$ before ${ }^{111} \mathrm{In}$-tetrazine injection. Data represent average $\pm \operatorname{SD}(n=4)$. $n u / n u$, was used in that study. The renal uptake of ${ }^{111} \mathrm{In}-\mathrm{DOTA}-\mathrm{Z}_{2395}$ at $1 \mathrm{~h}$ after injection was $284 \pm 22 \% \mathrm{ID} / \mathrm{g}$. Thus, pretargeting provided more than a 56-fold reduction of renal uptake of a radiometal in comparison with direct targeting. The micro-SPECT images (Fig. 7) demonstrate the difference clearly, confirming our hypothesis that rapid internalization of Affibody molecules in the kidneys would remove $\mathrm{Z}_{2395}$-TCO from the lumen of proximal tubuli and make it inaccessible for the radiometal-labeled tetrazine.

The preinjection of $\mathrm{Z}_{2395}$-TCO results in a higher blood retention and higher renal uptake of ${ }^{111}$ In-tetrazine (Fig. 5). It is likely that the residual $\mathrm{Z}_{2395}-\mathrm{TCO}$ in blood reacts with injected tetrazine. Moreover, the elevated renal uptake in this case is, most likely, due to reabsorption of ${ }^{111}$ In-tetrazine- $Z_{2395}$-TCO adduct. We tested the hypothesis that it is possible to saturate $\mathrm{Z}_{2395} \mathrm{TCO}$ in the blood without affecting tumor uptake. However, an increase of tetrazine-toAffibody ratio from 1:1 to 5:1 did not decrease either the blood concentration or the renal uptake significantly. Apparently, alternative approaches are required for reduction of the blood retention of radiometal-labeled tetrazine after $\mathrm{Z}_{2395}$-TCO preinjection.

A surprising finding of this study is the more rapid blood clearance and significantly lower uptake of ${ }^{177} \mathrm{Lu}$-tetrazine in tumors and kidneys than of ${ }^{111}$ In-tetrazine. The only difference between these substances is the DOTA-metal complex geometry. DOTA derivative complex with $\mathrm{In}$ (III) is a monocapped trigonal prism geometry whereas the complex with $\mathrm{Lu}(\mathrm{III})$ might have square antiprism or twisted square antiprism geometries (27). However, it was shown earlier that such subtle differences might be associated with substantial differences in the biodistribution of radiolabeled peptides $(26,28)$.

The preliminary assessment of dosimetry (Supplemental Table 2) demonstrated that the kidney is a critical organ. The tumor dose might exceed the renal dose approximately 1.4-fold. With a renal absorbed dose limit of 27 Gy (29), this would enable a tumor dose 


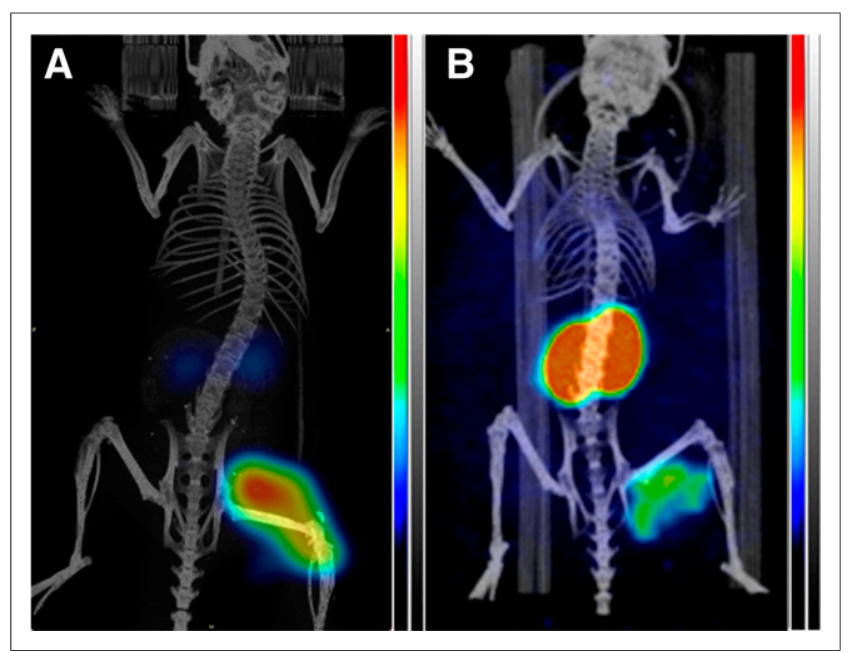

FIGURE 7. (A) SPECT/CT image of mouse bearing SKOV-3 xenograft pretargeted with $30 \mu \mathrm{g}(4.1 \mathrm{nmol})$ of $\mathrm{Z}_{2395}-\mathrm{TCO}$ and $4 \mathrm{~h}$ later injected with ${ }^{111} \mathrm{In}$-tetrazine injection. Image was acquired $1 \mathrm{~h}$ after injection of ${ }^{111}$ In-tetrazine. (B) SPECT/CT image of mouse injected directly with ${ }^{111} \mathrm{In}-\mathrm{DOTA}-\mathrm{Z}_{2395}(1 \mathrm{~h})$. (Reprinted with permission of (26)).

of $37 \mathrm{~Gy}$. This dose might be sufficient to obtain a palliation effect with some tumor shrinkage (30). Apparently, further optimization of the method is required. The most obvious approaches, such as an increase of the time span between the injection of primary and secondary agents or modification of tetrazine-to-Affibody ratio, appeared to be inefficient. A possible way might be modification of the physicochemical properties of the chelator-tetrazine conjugate by variation of PEG length, chelator structure, or the used therapeutic radionuclide.

\section{CONCLUSION}

This study provides proof of principle for bioorthogonal chemistrymediated ESP-based pretargeting. The pretargeting enabled more than a 50-fold reduction of renal uptake of radiometals in comparison with direct ESP-based targeting. After optimization, this strategy may be used for radionuclide therapy.

\section{DISCLOSURE}

The costs of publication of this article were defrayed in part by the payment of page charges. Therefore, and solely to indicate this fact, this article is hereby marked "advertisement" in accordance with 18 USC section 1734 . This research was financially supported by grants from the Swedish Cancer Society (grant 2012/354) and the Swedish Research Council (grants 521-2012-2228 and 621-2013-5135). No other potential conflict of interest relevant to this article was reported.

\section{REFERENCES}

1. Tolmachev V, Stone-Elander S, Orlova A. Radiolabelled receptor-tyrosine-kinase targeting drugs for patient stratification and monitoring of therapy response: prospects and pitfalls. Lancet Oncol. 2010;11:992-1000.

2. Pouget JP, Navarro-Teulon I, Bardiès M, et al. Clinical radioimmunotherapy: the role of radiobiology. Nat Rev Clin Oncol. 2011;8:720-734.

3. Binz HK, Amstutz P, Pluckthun A. Engineering novel binding proteins from nonimmunoglobulin domains. Nat Biotechnol. 2005;23:1257-1268.

4. Ahlgren S, Tolmachev V. Radionuclide molecular imaging using affibody molecules. Curr Pharm Biotechnol. 2010;11:581-589.

5. Zahnd C, Kawe M, Stumpp MT, et al. Efficient tumor targeting with high-affinity designed ankyrin repeat proteins: effects of affinity and molecular size. Cancer Res. 2010;70:1595-1605.
6. Hackel BJ, Kimura RH, Gambhir SS. Use of ${ }^{64} \mathrm{Cu}$-labeled fibronectin domain with EGFR-overexpressing tumor xenograft: molecular imaging. Radiology. 2012; 263:179-188.

7. Terwisscha van Scheltinga AG, Lub-de Hooge MN, Hinner MJ, et al. In vivo visualization of MET tumor expression and anticalin biodistribution with the MET-specific anticalin ${ }^{89} \mathrm{Zr}$-PRS-110 PET tracer. J Nucl Med. 2014;55:665-671.

8. Ackerman SE, Currier NV, Bergen JM, Cochran JR. Cystine-knot peptides: emerging tools for cancer imaging and therapy. Expert Rev Proteomics. 2014;11:561-572.

9. Garousi J, Lindbo S, Åstrand M, et al. ADAPT, a novel scaffold protein-based probe for radionuclide imaging of molecular targets in disseminated cancer. Cancer Res. 2015;75:4364-4371.

10. Sörensen J, Sandberg D, Sandström M, et al. First-in-human molecular imaging of HER2 expression in breast cancer metastases using the ${ }^{111} \mathrm{In}-\mathrm{ABY}-025$ affibody molecule. J Nucl Med. 2014;55:730-735.

11. Fortin MA, Orlova A, Malmström PU, Tolmachev V. Labelling chemistry and characterization of $\left[{ }^{90} \mathrm{Y} /{ }^{177} \mathrm{Lu}\right]-D O T A-Z H E R 2: 342-3$ affibody molecule, a candidate agent for locoregional treatment of urinary bladder carcinoma. Int $\mathrm{J} \mathrm{Mol}$ Med. 2007;19:285-291.

12. Wållberg H, Orlova A. Slow internalization of anti-HER2 synthetic affibody monomer ${ }^{111}$ In-DOTA-ZHER2:342-pep2: implications for development of labeled tracers. Cancer Biother Radiopharm. 2008;23:435-442.

13. Tolmachev V, Rosik D, Wållberg H, et al. Imaging of EGFR expression in murine xenografts using site-specifically labelled anti-EGFR ${ }^{111}$ In-DOTA-Z EGFR:2377 affibody molecule: aspect of the injected tracer amount. Eur J Nucl Med Mol Imaging. 2010;37:613-622.

14. Orlova A, Hofström C, Strand J, et al. $\left[{ }^{99 \mathrm{~m}} \mathrm{Tc}(\mathrm{CO})_{3}\right]^{+}-(\mathrm{HE})_{3}-\mathrm{ZIGF} 1 \mathrm{R}: 4551$, a new affibody conjugate for visualization of insulin-like growth factor-1 receptor expression in malignant tumours. Eur J Nucl Med Mol Imaging. 2013;40:439-449.

15. Tolmachev V, Mume E, Sjöberg S, Frejd FY, Orlova A. Influence of valency and labelling chemistry on in vivo targeting using radioiodinated HER2-binding affibody molecules. Eur J Nucl Med Mol Imaging. 2009;36:692-701.

16. Orlova A, Tran TA, Ekblad T, Karlström AE, Tolmachev V. ${ }^{186}$ Re-maSGS-Z (HER2:342), a potential affibody conjugate for systemic therapy of HER2expressing tumours. Eur J Nucl Med Mol Imaging. 2010;37:260-269.

17. Altai $\mathrm{M}$, Wållberg $\mathrm{H}$, Honarvar $\mathrm{H}$, et al. ${ }^{188}$ Re-ZHER2:V2, a promising affibodybased targeting agent against HER2-expressing tumors: preclinical assessment. J Nucl Med. 2014;55:1842-1848.

18. Tolmachev V. Choice of radionuclides and radiolabeling techniques In: Stigbrand T, Carlsson J, Adams GP, eds. Targeted Radionuclide Tumor Therapy: Biological Aspects. New York, NY: Springer Science + Business Media B.V.; 2008:145-174.

19. van de Watering FC, Rijpkema M, Robillard M, Oyen WJ, Boerman OC. Pretargeted imaging and radioimmunotherapy of cancer using antibodies and bioorthogonal chemistry. Front Med (Lausanne). 2014;1:44.

20. Hnatowich DJ, Virzi F, Rusckowski M. Investigations of avidin and biotin for imaging applications. J Nucl Med. 1987;28:1294-1302.

21. Liu G, Mang'era K, Liu N, Gupta S, Rusckowski M, Hnatowich DJ. Tumor pretargeting in mice using 99mTc-labeled morpholino, a DNA analog. J Nucl Med. 2002;43:384-391.

22. Goldenberg DM, Chang CH, Rossi EA. J W, McBride, Sharkey RM. Pretargeted molecular imaging and radioimmunotherapy. Theranostics. 2012;2:523-540.

23. Rossin R, Verkerk PR, van den Bosch SM, et al. In vivo chemistry for pretargeted tumor imaging in live mice. Angew Chem Int Ed Engl. 2010;49:3375-3378.

24. Taylor MT, Blackman ML, Dmitrenko O, Fox JM. Design and synthesis of highly reactive dienophiles for the tetrazine-trans-cyclooctene ligation. $J$ Am Chem Soc. 2011;133:9646-9649.

25. Tolmachev V, Wållberg H, Sandström M, Hansson M, Wennborg A, Orlova A. Optimal specific radioactivity of anti-HER2 affibody molecules enables discrimination between xenografts with high and low HER2 expression levels. Eur J Nucl Med Mol Imaging. 2011;38:531-539.

26. Altai M, Strand J, Rosik D, et al. Influence of nuclides and chelators on imaging using affibody molecules: comparative evaluation of recombinant affibody molecules site-specifically labeled with ${ }^{68} \mathrm{Ga}$ and ${ }^{111} \mathrm{In}$ via maleimido derivatives of DOTA and NODAGA. Bioconjug Chem. 2013;24:1102-1109.

27. Correia JD, Paulo A, Raposinho PD, Santos I. Radiometallated peptides for molecular imaging and targeted therapy. Dalton Trans. 2011;40:6144-6167.

28. Heppeler A, Froidevaux S, Mäcke HR, et al. Radiometal-labelled macrocyclic chelator-derivatised somatostatin analogue with superb tumour targeting properties and potential for receptor rmediated internal radiotherapy. Chem Eur J. 1999;5:1974-1981.

29. Valkema R, Pauwels SA, Kvols LK, et al. Long-term follow-up of renal function after peptide receptor radiation therapy with ${ }^{90} \mathrm{Y}$-DOTA(0), Tyr(3)-octreotide and ${ }^{177}$ Lu-DOTA(0), Tyr(3)-octreotate. J Nucl Med. 2005;46(suppl 1):83S-91S.

30. Ilan E, Sandström M, Wassberg C, et al. Dose response of pancreatic neuroendocrine tumors treated with peptide receptor radionuclide therapy using ${ }^{177} \mathrm{Lu}-$ DOTATATE. J Nucl Med. 2015;56:177-182. 